Review

\title{
Current Status of Carcinogenicity Assessment of Peroxisome Proliferator-Activated Receptor Agonists by the US FDA and a Mode-of-Action Approach to the Carcinogenic Potential
}

\author{
Toyohiko Aoki ${ }^{1}$ \\ ${ }^{1}$ Drug Safety Research Laboratories, Eisai Co., Ltd., 1 Kawashimatakehaya-machi, Kakamigahara-shi, Gifu 501-6195, \\ Japan
}

\begin{abstract}
Since it has been revealed that PPAR (Peroxisome Proliferator-Activated Receptor) agonists induce various types of tumors in various organs and tissues in rodents, the US FDA has been requesting performance of 2-year carcinogenicity studies prior to initiation of clinical studies longer than 6 months, and does not accept data from alternative carcinogenicity studies such as those in transgenic mouse models, which are recommended in the ICH S1B guideline. In general, although PPAR agonists do not possess genotoxic potential, the tissue distribution of PPAR does correspond to the target organs and tissues of tumor induction, and carcinogenic potential is closely correlated with potency of PPAR agonistic effect. It is thus not possible to rule out the possibility that the mode of action (MOA) of tumorigenesis by PPAR agonists is receptor- mediated. The ILSI-HESI PPAR Agonist Project was organized and is currently conducting collaborative research to elucidate the MOA of PPAR agonist-induced carcinogenicity (for urinary bladder tumor, hemangioma/hemangiosarcoma, and fibrosarcoma/liposarcoma) and to evaluate the human relevance of the results of rodent bioassays of PPAR agonists. In this paper, carcinogenicity data on PPAR agonists disclosed by the CDER of the US FDA and current activities of the ILSI-HESI PPAR Agonist Project are explained, and the possible usefulness of transgenic mouse models, especially rasH2 mice, for assessing carcinogenic potential and the MOA of PPAR agonists are addressed. (J Toxicol Pathol 2007; 20: 197-202)
\end{abstract}

Key words: PPAR agonist, carcinogenicity, transgenic mouse model, rasH2 mouse

\section{Introduction}

PPARs (Peroxisome Proliferator-Activated Receptors) are members of the nuclear receptor superfamily. The mechanism of activation of PPAR gene transcription is shown in Fig. 1. When PPAR ligands such as PPAR agonists are bound to PPAR, PPAR and RXR (retinoid X receptor) produce heterodimers which bind the specific responsive element (PPRE: peroxisome proliferator responsive element) upstream of the promoter region in the target gene, resulting in activating transcription of the target genes $^{1,2}$.

Three distinct receptor types belonging to this family have been identified: alpha $(\alpha)$, gamma $(\gamma)$, and beta/delta $(\beta / \delta)^{3,4}$. PPAR $\alpha$ expressed in liver, brown adipose tissue, heart, kidney and skeletal muscle exerts effects on lipid and

Received: 3 September 2007, Accepted: 5 September 2007 Mailing address: Toyohiko Aoki, Drug Safety Research Laboratories, Eisai Co., Ltd., 1 Kawashimatakehaya-machi, Kakamigaraha-shi, Gifu 501-6195, Japan

TEL: 81-58689-4720 FAX: 81-58689-5292

E-mail: t2-aoki@hhc.eisai.co.jp lipoprotein metabolism through peroxisome proliferation. PPAR $\gamma$ expressed in heart, white adipose tissue, urinary bladder, large intestine, and immune organs, improves insulin resistance caused by fat storage, adipocyte differentiation, and/or anti-inflammatory effects. On the

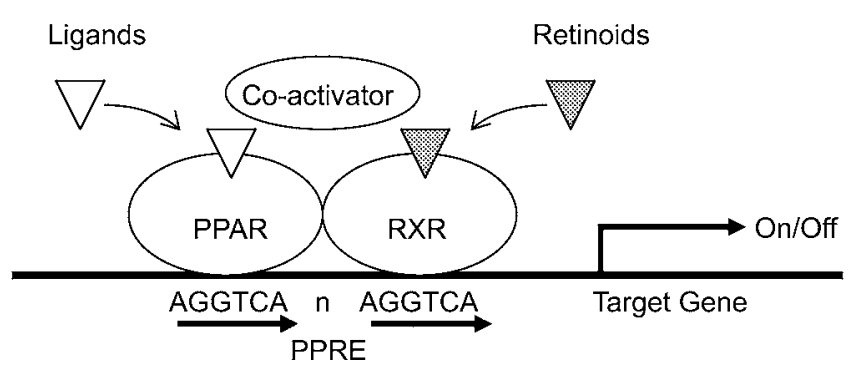

Fig. 1. When PPAR ligands such as PPAR agonists are bound to PPAR, PPAR and RXR produce heterodimers which bind the specific responsive element (PPRE) upstream of the promoter region in the target gene, resulting in activating of transcription of target genes. PPAR: peroxisome proliferatoractivated receptor, RXR: retinoid X receptor, PPRE: peroxisome proliferator responsive element. 
other hand, PPAR $\delta(\beta)$ is distributed in organs and tissues throughout the body including skeletal muscle and cardiac muscle, and assists cell growth and adipocyte differentiation, although the details of its pharmacological and physiologic functions have yet to be fully determined. The organ and tissue distributions and pharmacological and physiological actions of these three types of PPARs are summarized in Table 1.

Due to their potential pharmacologic activities in treating so-called "metabolic syndrome", many PPAR agonists have been developed or are under development as pharmaceuticals by a number of pharmaceutical companies (Table 2). PPAR $\alpha$ agonists, which mainly lower blood triglyceride levels, are used for the treatment for dyslipidemia clinically, and a numbers of fibrates are currently available on the market. PPAR $\gamma$ agonists, which improve insulin sensitivity, are used for type 2 diabetes: some derivatives of thiazolidines have been developed, and pioglitazone and rosiglitazone are currently available commercially, although trogliazone was withdrawn from the market due to clinical hepatic adverse events. Since PPAR $\alpha / \gamma$ dual agonists having both $\alpha$ and $\gamma$ agonistic effects are expected to be useful in treating type 2 diabetes and its underlying condition, dyslipidemias, many pharmaceutical companies have developed them as agents for the treatment of type 2 diabetes. PPAR $\beta$ agonists and pan-agonists are under development as agents for the treatment of obesity, dyslipidemias, and type 2 diabetes. However, no $\alpha / \gamma$ dual agonists, $\beta$ agonists, or pan-agonists have been approved by regulatory agencies for clinical use. One of the reasons for this is concern regarding preclinical safety, principally involving the carcinogenicity of these classes of compound ${ }^{5-7}$.

\section{Results of Carcinogenicity Studies of PPAR $\gamma$ and $\alpha / \gamma$ dual Agonists}

The Center for Drug Evaluation and Research (CDER) of the Food and Drug Administration (FDA) disclosed findings of tumor development with PPAR $\gamma$ and PPAR $\gamma / \alpha$ dual agonists in carcinogenicity studies, and data on 12 agonists (6 PPAR $\gamma$ agonists, 6 PPAR $\gamma / \alpha$ dual agonists) are publicly available (Table 3-1 and 3-2) ${ }^{7-10}$. Common tumor findings in rodent carcinogenicity studies of PPAR agonists are hemangioma/hemangiosarcoma, urinary bladder/renal pelvic tumors, and lipoma/liposarcoma.

1) Hemangioma/hemangiosarcoma: These tumors were observed in multiple organs such as the spleen, liver, skin and adipose tissues of male and female CD-1 and B6C3F1 mice and hamsters treated with 8/12 PPAR agonists ( $4 \gamma$ agonists including troglitazone ${ }^{11,12}$ and 4 dual agonists). It has also been reported that hemangiomatous hyperplasia and angiectasia were observed in rodent and non-rodent species treated with the other compounds of the same class.

2) Urinary bladder/renal pelvic tumors: Transitional papilloma and carcinoma originated from urothelium were found in the urinary bladder and renal pelvis of SD, Wistar
Table 1. Tissue Distribution and Physiological Roles of PPARs

\begin{tabular}{|c|c|}
\hline Subtype & Tissue distribution \\
\hline $\operatorname{PPAR} \alpha$ & $\begin{array}{l}\text { Liver, Kidney, Heart, Brown adipose tissue, Skeletal } \\
\text { muscles, Large intestine, Pancreas, Adrenals }\end{array}$ \\
\hline $\operatorname{PPAR} \beta / \delta$ & Ubiquitous \\
\hline PPAR $\gamma$ & $\begin{array}{l}\text { Heart, Kidneys, Spleen, Large intestine, White } \\
\text { adipose tissue, Urinary bladder, Smooth muscle, } \\
\text { Mammary glands, Macrophages }\end{array}$ \\
\hline Subtype & Physiological functions \\
\hline \multirow[t]{5}{*}{$\operatorname{PPAR} \alpha$} & Fatty acid oxidation \\
\hline & Lowering of triglycerides, LDL \\
\hline & Increasing HDL \\
\hline & Wound healing \\
\hline & Peroxisome proliferation \\
\hline \multirow[t]{5}{*}{$\operatorname{PPAR} \beta / \delta$} & Lipid metabolism \\
\hline & Lowering of triglycerides \\
\hline & Cell proliferation \\
\hline & Adipocyte differentiation \\
\hline & Embryonic implantation \\
\hline \multirow[t]{6}{*}{$\operatorname{PPAR} \gamma$} & Improving insulin sensitivity \\
\hline & Lowering of glucose level \\
\hline & Adipocyte differentiation \\
\hline & Lipid storage \\
\hline & Anti-inflammatory effects \\
\hline & Maturation of macrophages \\
\hline
\end{tabular}

and Fisher strain rats of both sexes treated with $5 / 6$ dual agonists and one $\gamma$ agonist (pioglitazone). Three PPAR agonists were found to be urinary bladder tumor promoters in the rat initiation-promotion model using N-butyl-N-(4hydroxybutyl) nitrosamine (BBN) as an initiator. Furthermore, mucosal hyperplasia and vacuolization in the urinary bladder were observed in dogs and monkeys treated with some PPAR $\gamma$ or dual agonists.

3) Lipoma/liposarcoma: PPAR $\gamma$ is related to adipose differentiation in all animal species tested. These tumors were found in 5 rat and one mouse study of $3 \gamma$ agonists and 3 dual agonists.

Other tumor findings with PPAR agonists include the following: 3/6 dual agonists produced skin fibrosarcoma and mammary adenocarcinoma in one mouse and 2 rat carcinogenicity studies, in addition to gallbladder adenoma, leiomyosarcoma, hepatic tumors (hepatocellular adenoma/ carcinoma), and renal tubular sarcomatous tumors in a few mouse and rat carcinogenicity studies of PPAR agonists.

\section{The FDA's Response to the Carcinogenic Potential of PPAR Agonists}

Since PPAR agonists generally yield negative results on the standard in vitro and in vivo genotoxicity test battery, it is likely that tumor induction by PPAR agonists involves nongenotoxic mechanisms. The finding that sites of tumor development are consistent with the distribution of PPAR implies that carcinogenic potentials is correlated with the 
Table 2 PPAR Agonists Marketed or in Development and Their Clinical Indications

\begin{tabular}{lll}
\hline Class & \multicolumn{1}{c}{ Compound } & Clinical indication \\
\hline PPAR $\alpha$ agonist & Fibrates (Clofibrate, Bezafibrate, Fenofibrate, Gemfibrozil, etc.) & Dyslipidemia \\
PPAR $\beta(\delta)$ agonist & GW501516, L-165041 & Obesity, dyslipidemia \\
PPAR $\gamma$ agonist & Thiazolidinediones (Troglitazone*, Rosigliazone, Piogliazone) & Diabetes \\
PPAR $\alpha / \gamma$ agonist & Muraglitazar, Ragaglitazar, Tesagliazar, Naveglitazar, & Diabetes, dyslipidemia \\
(PPAR dual agonist) & AVE-0847, TAK-654, ONO-5129 & Diabetes, dyslipidemia, obesity \\
PPAR $\alpha / \beta(\delta) / \gamma$ agonist & GW677954, PLX204 & \\
(PPAR pan agonist) & &
\end{tabular}

*Withdrawn from market due to clinical hepatic adverse events.

Table 3-1. Tumor Findings with PPAR $\gamma$ Agonists*

\begin{tabular}{llllll}
\hline Drug & Hemangiosarcoma & U. bladder/Kidney & Lipoma/Sarcoma & Liver & Other \\
\hline $\begin{array}{l}\text { Trogliazone } \\
\text { Rosiglitazone }\end{array}$ & Mouse (M, F) & & Rat (M, F) & Mouse (F) & \\
$\begin{array}{l}\text { Piogliazone } \\
\text { A }\end{array}$ & Rouse (M, F) & & Rat (M, F) & & Mouse (Cervix) \\
B & Mouse (M, F) & Rat (M) & & Mouse (Gallbladder, M, F) \\
C & Mouse (M, F) & & & Rat (F) & Rat (Stomach, M) \\
\hline
\end{tabular}

Table 3-2. Tumor Findings with PPAR Dual Agonists*

\begin{tabular}{llllll}
\hline Drug & Hemangiosarcoma & U. bladder/Kidney & Fibrosarcoma & Liposarcoma & Other \\
\hline D & No data & Rat (Pelvis, M, F) & & Rat (M) & Liver, Testes, Thyroids, Mammary \\
E & Mouse (M, F) & Rat (M, F) & Rat (F) & Mouse, Rat (M, F) & Liver, Mammary \\
F & Mouse (M, F) & Rat (M, F) & Rat (M, F) & & Stomach, Mammary \\
G & Hamster (F) & & Rat (M, F) & $\begin{array}{l}\text { Liver, Thyroids } \\
\text { Gallbladder }\end{array}$ \\
Muraglitazar & & Rat (M) & & & Leukemia, Uterus \\
H & Mouse (M, F) & Rat (M, F) & & & (M) \\
\hline
\end{tabular}

* Data from EI Hage, J: Toxicity Profiles of Peroxisome Proliferator-Activated Receptor (PPAR) Agonists and Preclinical Safety Profile for Muraglitazar, Endocrinologic and Metabolic Drugs Advisory Committee, September 2005.

potency of PPAR agonist effect. Based on this, PPAR agonists are classified as "probable human carcinogens" according to the criteria of the Environmental Protection Agency (EPA) ${ }^{13}$ and International Agency for Research on Cancer (IARC) ${ }^{14}$. Since the mode of action (MOA) of carcinogenicity has not yet been fully elucidated for most types of PPAR-induced tumors, it is the FDA's position that the human relevance of these tumors cannot be ruled out, and it recommends completion of a 2-year carcinogenicity study and submission of draft reports for agency review prior to initiation of clinical studies longer than 6 months in duration for all PPAR agonists under development. In addition, transgenic mouse models, which are cited in the ICH 1B guideline ${ }^{15}$, are not accepted as alternatives for 2-year mouse carcinogenicity study due to the prevalence of positive tumor findings with PPAR agonists of the same class. It has been suggested that a statement that tumor findings are generally observed in rodent carcinogenicity studies of this class of compound be included in investigator brochures and informed consent forms for all PPAR agonists. Clinical development of several PPAR agonists has been discontinued due to findings of tumor development at all doses, or limited margins of safety in terms of exposure in animals and humans in 2-year carcinogenicity studies.

\section{MOA of Carcinogenicity of PPAR Agonists and the ILSI-HESI PPAR Agonist Project}

Discussion of the FDA's recommendation on development of PPAR agonists at the DIA meeting in June 2004 was followed by organization of the PPAR InterIndustry Consortium in July 2004, aiming at common understanding of the carcinogenicity of PPAR agonists in rodents and assessment of the relevant risks to humans. When the Health and Environmental Sciences Institute (HESI), a global branch of International Life Sciences Institute (ILSI), launched the PPAR Agonist Project Committee in 2005, a number of US, EU and Japanese pharmaceutical companies including the PPAR InterIndustry Consortium members, representatives of the 


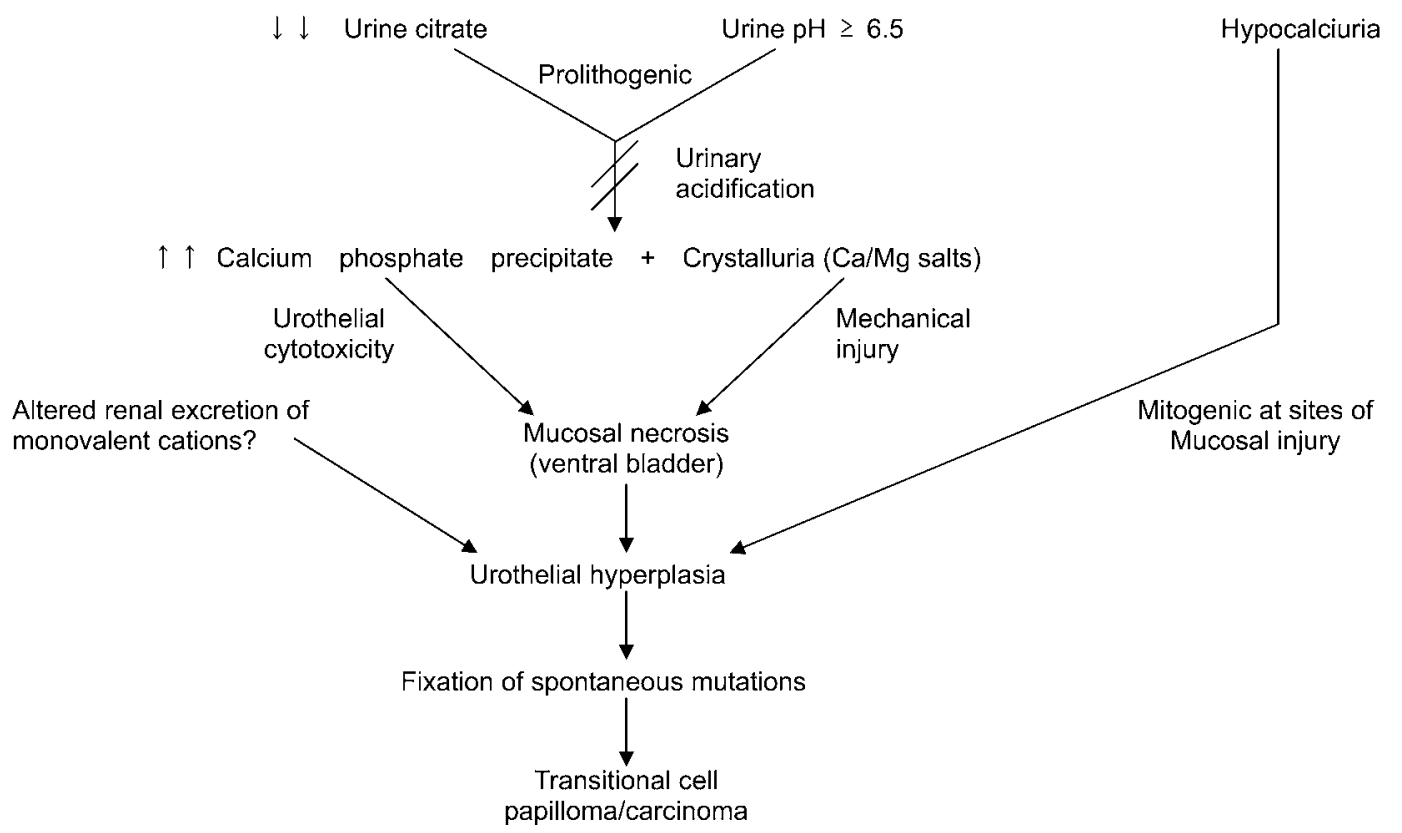

Fig. 2. Proposed MOA for PPAR-Induced Urinary Bladder and Renal Pelvic Tumors in Rats. Prolithogenic changes in urine composition such as decreased urine citrate level and alkaluria result in increased calcium phosphate precipitate and crystalluria. Mucosal necrosis of the urinary bladder, mainly in the ventral mucosa, occurs as a result of cytotoxic effects of calcium phosphate precipitates and mechanical injury by crystalluria. In addition to mucosal necrosis, enhanced mitogenic activity in the injured bladder mucosa by hypocalciuria and changes in urine electrolyte concentration induce urothelial hyperplasia. Sustained urothelial proliferation may cause fixation of spontaneous mutation of mucosal cells, and finally develop tumors in urinary bladder and/or renal pelvis.

regulatory agencies, and academics participated in this project $^{16,17}$. The goals of the project were to build a MOA framework for each type of tumor induced by PPAR agonists, and to ascertain its relevance to human risks. In the project, working groups on the three types of tumors caused by administration of PPAR agonists, 1) urinary bladder tumor, 2) hemangiosarcoma and 3) fibrosarcoma/ liposarcoma were established, and requested that participating companies share data and histology slides from the carcinogenicity studies and to financially support for histopathological peer review. The project also requested provision of drug substances for mechanistic studies designed to elucidate the MOA of carcinogenicity.

The Urinary Bladder Working Group proposed a MOA for PPAR agonist-induced urinary bladder/renal pelvic tumors in rats (Fig. 2) ${ }^{18}$. Prolithogenic changes in urine composition such as decreased urine citrate level and alkaluria result in increased calcium phosphate precipitate and crystalluria. Mucosal necrosis of the urinary bladder, mainly in the ventral mucosa, occurs as a result of cytotoxic effects of calcium phosphate precipitates and mechanical injury by crystalluria. In addition to mucosal necrosis, enhanced mitogenic activity in the injured bladder mucosa by hypocalciuria and changes in urine electrolyte concentration induce urothelial hyperplasia. Sustained urothelial proliferation may cause fixation of spontaneous mutation of mucosal cells, and finally develop tumors in urinary bladder and/or renal pelvis. Recently, a 2-year carcinogenicity study and a mechanistic study of
Muragliazar, a PPAR dual agonist, provided some evidence for the proposed MOA ${ }^{19,20}$. Similar working hypotheses on MOAs are being proposed by the Hemangioma/ Hemangiosarcoma and Fibrosarcoma/Liposarcoma Working Groups of the project, and further work toward elucidation of MOAs and evaluation of human risks is expected. Mechanistic studies for hemangiosarcoma by a PPAR $\gamma$ agonist and fibrosarcoma induced by a PPAR $\gamma$ or dual agonist have recently been reported ${ }^{21,22}$. MOA and the human relevance of PPAR $\alpha$ agonist-induced rodent tumors were previously investigated by the ILSI-HESI, and results of this investigation were published ${ }^{23}$.

\section{Usefulness of Transgenic Animal Models}

Although transgenic mouse models for carcinogenic evaluation for PPAR agonists are not acceptable to the FDA, we should nevertheless consider the regulatory feasibility and acceptability of these models.

The ICH 1B guideline ${ }^{15}$ defines several transgenic mouse assays including the $\mathrm{p} 53+/$ - deficient mode ${ }^{24}, \mathrm{Tg}$. AC model ${ }^{25}$, TgHras 2 model $^{26}$, and Xpa deficient model ${ }^{27}$ as alternative methods for additional in vivo testing of carcinogenicity. Although the FDA has recommended the p53+/- deficient mouse model as an alternative for 2-year carcinogenicity study, the $\mathrm{p} 53+/$ - deficient mice model is not be applicable to carcinogenicity assessment of PPAR agonists, since non-genotoxic compounds are undetectable in this model and PPAR agonists generally yield negative 
results in the standard genotoxicity studies. The Tg.AC mice and Xpa deficient mice cannot be used either, since they are limited to specific purposes. On the other hand, there is some evidence that the TgHras 2 mouse model (rasH2 mouse model), a transgenic mouse over-expressing the human proto-oncogene, c-Ha-ras, can detect nongenotoxic as well as genotoxic carcinogens ${ }^{28}$. Hemangioma and hemangiosarcoma, which are commonly observed in mice chronically treated with PPAR $\gamma$ and dual agonists, are observed at higher incidence as spontaneous tumors in rasH2 mice ${ }^{26}$. Mitsumori et al. recently reported increased incidences of hemangioma and hemangiosarcoma in rasH2 mice after 26-week treatment with troglitazone, a PPAR $\gamma$ agonist ${ }^{29}$. In tumor tissues of the treated mice, overexpression of transgene and related genes for induction of hemangioma and hemangiosarcoma including osteopontin, CKs1b, Tpm1, Reck, and gelsolin were shown in DNA microarray analyses. Some PPAR $\alpha$ agonists, including clofibrate 30,31 and DEHP (deiethyl hexylphthalate $)^{32}$ have been reported to induce liver tumors in rasH2 mice. Despite limited information on carcinogenicity studies of PPAR agonists in rasH2 mice, findings strongly suggest that this model would be useful for assessing carcinogenic potential and the MOA of carcinogenicity by PPAR agonists.

\section{References}

1. Fiévet C, Fruchart J-C, and Staels B. PPAR $\alpha$ and PPAR $\gamma$ dual agonists for the treatment of type 2 diabetes and the metabolic syndrome. Curr Opin Pharmacol. 6: 606-614. 2006.

2. Shulman AI and Mangelsdorf DJ. Retinoid X receptor hererodimers in the metabolic syndrome. N Engl J Med. 353: 604-615. 2005.

3. Berger $\mathrm{J}$ and Moller DE. The mechanisms of action of PPARs. Annu Rev Med. 53: 409-435. 2002.

4. Takeyama K, Kodera Y, Suzawa M, and Kato S. Peroxisome proliferator-activated receptor (PPAR)-structure, function, tissue distribution, gene expression. Nippon Rinsho. 58: 357-363. 2000 (In Japanese).

5. Peraza MA, Burdick AD, Marin HE, Gonzalez FJ, and Peters JM. The toxicology of ligands for peroxisome proliferator-activated receptors (PPAR). Toxicl Sci. 90: 269-295. 2006.

6. El-Hage J. Preclinical and clinical safety assessment for PPAR agonists. DIA meeting. Washington DC. 2004.

7. El Hage J. Toxicity profiles of peroxisome proliferatoractivated receptor (PPAR) agonists and preclinical safety profile for muraglitazar, Endocrinologic and Metabolic Drugs Advisory Committee. September 9. 2005.

8. EI-Hage J. PPAR agonist carcinogenicity. FDA CDER News along the Pike. 10: 5-6. 2004.

9. EI-Hage J. Peroxisome proliferation-activated receptor agonists: Carcinogenicity findings and regulatory recommendations. International Atherosclerosis Society Symposium on PPAR. Monte Calro. 2005.

10. El-Hage J. Peroxisome proliferator-activated receptor agonists: Carcinogenicity findings and regulatory recommendations, $30^{\text {th }}$ Annual Winter Toxicology Forum, Washington DC. 2005.

11. Duddy SK, Gorospe SM, Bleavins MR, and de la Iglesia FA. Spontaneous and thiazolidinedione-induced B6C3F1 mouse hemangiosarcomes exhibit low ras oncogene mutation frequencies. Toxicol Appl Pharmacol. 160: 133-140. 1999.

12. Herman JR, Dethloff LA, McGuire EJ, Parker RF, Walsh KM, Gough AW, Masuda H, and de la Iglesia FA. Rodent carcinogenicity with the thiazolidinedione antidiabetic agent troglitazone. Toxicol Sci. 68: 226-236. 2002.

13. US Environmental Protection Agency. Guidelines for carcinogen risk assessment. Federal Register 51 (185): 33992. 1986.

14. WHO. WHO International Agency for Research on Cancer. Preamble to the IARC Monographs on the Evaluation of Carcinogenic Risk of Chemicals to Humans. 2004.

15. ICH. ICH harmonized tripartite guideline. Testing for carcinogenicity of pharmaceuticals. 1997.

16. ILSI-HESI. PPAR agonist Project committee. 2006 Annual report, 32-33. 2006.

17. Storer RD. Risk management of preclinical carcinogenicity findings with PPAR (Peroxisome proliferator-activated receptor) agonists. $30^{\text {th }}$ Annual Winter Toxicology Forum. Washington DC. 2005.

18. Cohen SM. Effects of PPAR $\gamma$ and combined agonists on the urinary tract of rats and other species. Toxicol Sci. 87: $322-$ 327. 2005.

19. Tannehill-Gregg SH, Sanderson TP, Minnema D, Voelker R, Ulland B, Cohen SM, Arnold LL, Schilling BE, Waites $\mathrm{CR}$, and Diminick MA. Rodent carcinogenicity profile of the antidiabetic dual PPAR $\alpha$ and $\gamma$ agonist Muraglitazar. Toxiol Sci. 98: 258-270. 2007.

20. Van Vleet TR, White MR, Sanderson TP, Cohen SM, Cano M, Arnold LI, Waites CR, Schilling BE, Mitroka J, and Dominick MA. Subchronic urinary bladder effects of muraglitazar in male rats. Toxicol Sci. 96: 58-71. 2007.

21. Storer RD. Investigaive approaches to understanding the mode of action and human relevance of PPAR $\gamma$ agonist induced hemangiosarcoma in mice. The Toxicologist, Supplement to Toxicological Sciences. 90: 68. 2006.

22. Hellmold H, Zhang H, Andersson U, Blomgren B, Holland T, Berg AL, Elebring M, Sjogren N, Bamberg K, Dahl B, Westerberg R, Diller B, Tugwood J, Tugwood J, Roberts R, Lundholm E, Camejo G, Skanberg I, and Evans J. Tesaglitazar, a PPAR $\alpha / \gamma$ agonist, induces interstitial mesenchymal cell DNA synthesis and fibrosarcomas in subcutaneous tissues in rats. Toxicol Sci. 98: 63-74. 2007.

23. Klaunig JE, Babich MA, Baetcke KP, Cook JC, Corton JC, David RM, DeLuca JG, Lai DY, McKee RH, Peters JM, Roberts RA, and Fenner-Crisp PA. PPAR $\alpha$ agonist-induced rodent tumors: modes of action and human relevance. Critical Review Toxicol. 33: 655-780. 2003.

24. Storer RD, French JE, Haseman J, Hajian G, LeGrand EK, Long GG, Mixson LA, Ochoa R, Sagartz JE, and Soper KA. p53 $3^{-/+}$hemizygous knockout mouse: Overview of available data. Toxicol Pathol. 29(Suppl). 30-50. 2001.

25. Eastin WC, Mennear JH, Tennant RW, Stoll RE, Branstetter DG, Bucher JR, McCullough B, Binder RL, Spalding JW, and Mahler JF. Tg. AC genetically altered mouse: Assay working group overview of available data. Toxicol Pathol. 29(Suppl.). 60-80. 2001.

26. Usui T, Mutai M, Takaoka M, Soper KA, McCullough B, 
and Alden C. CB6F1-rasH2 mouse: Overview of available data. Toxicol Pathol. 29(Suppl). 90-108. 2001.

27. Van Kreijl CF, McAnulty PA, Beems RB, Vinckier A, van Steeg H, Fransson-Steen R, Alden CL, Forster R, van der Laan J-W, and Vandenberghe J. Xpa and Xpa/p53 $3^{+/-}$ knockout mice: Overview of available data. Toxicol Pathol. 29(Suppl). 117-127. 2001.

28. Tamaoki N. The ras $\mathrm{H} 2$ transgenic mouse: Nature of the model and mechanistic studies on tumorigenesis. Toxicol Pathol. 29(Suppl). 81-89. 2001.

29. Mitsumori K, Jin M, and Akahashi M. Usefulness and problems in carcinogenicity evaluation on pharmaceuticals using rasH2 mice. J Toxicol Pathol. 20: M6. 2007.
30. Aoki T, Imai T, Ando T, Dodo T, Kerns WD, Motooka S, and Tsukidate K. Effects of clofibrate in the CB6F1TgHras2 mice. J Toxicol Pathol. 15: 111-118. 2002.

31. Nesfield SR, Clarke CJ, Hoivik DJ, Miller RT, Allen JS, Selinger K, and Santostefano MJ. Evaluation of the carcinogenic potential of clofibrate in the ras $\mathrm{H} 2$ mouse. Int $\mathrm{J}$ Toxicol. 24: 301-311. 2005.

32. Toyosawa K, Okimoto K, Kobayashi I, Kitakawa E, Kohchi M, Koujitani T, Tanaka K, and Matsuoka N. Di(2ethylhexyl)phthalate induces hepatocellular adenoma in transgenic mice carrying a human prototype c-Ha-ras gene in a 26-week carcinogenicity study. Toxicol Pathol. 29: 458466. 2001 